\title{
XV. Hemihedrism of cuprite
}

\section{H.A. Miers M.A.}

To cite this article: H.A. Miers M.A. (1884) XV. Hemihedrism of cuprite, Philosophical Magazine Series 5, 18:111, 127-130, DOI: 10.1080/14786448408627577

To link to this article: http://dx.doi.org/10.1080/14786448408627577

$$
\text { 册 Published online: } 29 \text { Apr } 2009 .
$$

Submit your article to this journal 준

LII Article views: 2

Q View related articles $\asymp$ 
Perhaps the most salient fact concerning this group is that the methyl compound is intermediate in these of its physical properties between the ethyl and the amyl members. So interesting did this relationship appear, that we have determined the specific gravities of the three salts. Turpentine was used as the liquid displaced. The dry salt having been weighed in the specific-gravity bottle, a little turpentine was added and the air exhausted. The bottle was subsequently filled with turpentine in the usual way. The air-temperature was $19^{\circ} \cdot 6$, and the specific gravity of the turpentine compared with water at the same temperature was 0.86838 . It was found that

$$
\text { at } 19^{\circ} \cdot 6\left\{\begin{aligned}
\text { sp. grav. of sulphomethylate of potassium }=2 \cdot 097, \\
, \quad " \quad \text { sulphoethylate of potassium }=1 \cdot 843, \\
, \quad \text { sulphoamylate of potassium }=1 \cdot 144 .
\end{aligned}\right.
$$

Accordingly the densities of the salts are in the inverse order of their molecular weights, and the ethyl compound is in this respect in its usual place between the amyl and methyl relatives.

Physical Laboratory, Science Schools, South Kensington.

XV. Hemihedrism of Cuprite. By H. A. Mrers, M.A, Assistant in the Mineral Department, British Museum*'.

[Plate VI.]

A LOOSE crystal of cuprite (about 4 millim. across), which had been collected by the late Mr. Richard Talling, and which were offered to the British Museum for purchase, was noticed by Mr. Thos. Davies as hemihedral in form.

Subsequently about twelve specimens were found, all from Wheal Phouix, Cornwall, belonging partly to the same collection and partly to the collection in the Museum, which are characterized by the same peculiarity. This hemihedral development I have been requested by Mr. Fletcher to describe.

It proves to be a mode of hemihedrism of great interest to the crystallographer as one which for more than sixty years has been regarded as theoretically possible, but which has not been hitherto obserred on any mineral, and has only recently been proved to exist on artificial sal-ammoniac.

The usual form of the erystals is shown in fig. 4 , where $a$ are the cube, 0 the octahedron, and $x$ the new hemihedral

* Communicated by the Author. 
faces. They vary from the habit of fig. 4 , in which the cube predominates, to the similar combination of octahedral habit in which the cube-faces are comparatively small, erystals of cubic habit being most common. The dodecahedron-faces $d$ often enter into the combination, as is shown in fig. 5, which represents a third distinct habit characterized by the predominance of the hemihedral form $x$. The only other form observed on these crystals is $\{211\}$. The cube, octahedron, and dodecahedron planes are bright and even, while the faces $x$ are bright, but slightly rounded and uneven; they are roughly striated parallel to their intersections with the octahedron, and sometimes parallel to the most remote of the three nearest cube-faces.

The angles, measured and calculated, are as follows :-

\begin{tabular}{|c|c|c|c|c|}
\hline \multicolumn{3}{|c|}{ Observed. } & \multicolumn{2}{|c|}{ Calculated. } \\
\hline Mean. & $\begin{array}{l}\text { No. of } \\
\text { edges. }\end{array}$ & Limits. & $x=(986)$. & $x=(875)$. \\
\hline$(100): x=47^{\circ} 30^{\prime}$ & 18 & $46^{\circ} 39^{\prime}-48^{\circ} 2 \dot{2}$ & $48^{\circ} \quad 0 \cdot 7^{\prime}$ & $47 \quad 4.7$ \\
\hline$(010): x=53 \quad 43$ & 18 & $5234-5549$ & $5330 \cdot 8$ & $5325 \cdot 5$ \\
\hline$(001): x=63$ & 18 & $6245-6453$ & $6330 \cdot 8$ & $6448 \cdot 6$ \\
\hline$(111): x=9$ & 11 & $854-1049$ & $914 \cdot 5$ & $1035 \cdot 6$ \\
\hline
\end{tabular}

The best measurements obtained for a single face $x$ to the three cube-faces were $47^{\circ} 50^{\prime}, 53^{\circ} 20^{\prime}, 64^{\circ} 4^{\prime}$.

The position of the faces $x$ in the figures shows that they afford an example of the hemihedrism which has been described in the text-books of Crystallography * from the time of Mohs as trapezohedral or gyroidal, and as a theoretically possible though hitherto unobserved mode of hemihedrism in the Cubic System. Within the last three years, however, it has been discovered as occurring on one, and has been suggested for another, artificial salt.

If alternate faces of the complete 48-faced figure be suppressed, two half-forms are obtained for which the cubic and dodecahedral planes are no longer planes of symmetry. It was made clear by Mohs $\dagger$ that these two half-forms are enantiomorphous, and may therefore be distinguished as right

* Groth, Physizalische Krystallographie, 1876, p. 221; Mallard, Traité de Crystallographie, 1879, i. p. 88 (Hemiédrie holonxe); Liebisch, Geometrisehe Krystallographie, 1881, p. 246 ( $\gamma\{\mathrm{h} \mathrm{kl}\})$.

+ Mohs, Grundriss der Mineralogie, i. 1822, p. 170. 
and left. With the notation of Miller they may be denoted respectively by $a\{\mathrm{kh} l\}$ and $a\{\mathrm{~h} k \mathrm{k}\}$.

The faces $x$ are therefore to be assigned to the half-form $a\{986\}$, though, as may be seen from the limits of variation in the above table, the numerical values of the indices cannot be assigned with absolute precision.

Fig. 1 represents the complete form $\{986\}$.

Fig. 2 represents the half-form $a\{986\}$, obtained by rejecting the shaded faces, and is the half-form peculiar to cuprite. This is Mohs' left pentagon-icositetrahedron.

Fig. 3 represents the half-form $a\{896\}$, obtained by retaining the shaded faces; this is Mohs' right pentagonicositetrahedron.

It may be noticed that this mode of hemihedrism only affects the form of the 48 -faced figure $\{\mathrm{h} \mathrm{kl}\}$; so that in the case of cuprite, in which such faces are very rare, it is not surprising that the hemihedral character has hitherto escaped attention. Hexakis-octahedron faces have been figured as occurring holohedrally by W. Phillips *, and Kokscharow $\dagger$, but in neither case have indices been ascribed to the faces.

Where such forms have been noticed upon specimens in the Museum, they are so nneven and irregular that neither their position nor their number can be satisfactorily determined.

The cases in which this trapezohedral hemihedrism has been already recorded are the following :-

(1) Tschermak $\ddagger$ observed small faces of $a\left\{\begin{array}{l}7 \\ 85\end{array} 5\right.$ on artificial crystals of sal-ammoniac, upon edges of the form $p=\left\{\begin{array}{llll}2 & 1 & 1\end{array}\right\}$.

$$
\begin{aligned}
& \text { Observed. } \\
& p:(121)=13^{\circ} 10^{\prime} \\
& p:(211)=21 \\
& \mid
\end{aligned}
$$

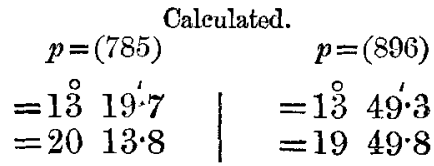

It is thus possible that the hemihedral faces of sal-ammoniac and of cuprite may belong to the same form ; but it is remarkable that the crystals of sal-ammoniac exhibit the right, and those of cuprite the left half-form.

(2) Ben-Saude § obtained by corrosion with water upon artificial crystals of mixed potassium and sodium chlorides faces which were obliquely striated in such a way as to suggest the presence of small asymmetric faces.

These crystals also exhibited "double refraction in sectors." Lastly, it has been a question of interest whether this mode

* Transactions of the Geological Society, vol. i. 1811, p. 37.

† Materialen zur Mineralogie Russtands, i. 1853, p. 84.

+ Min. und Petr. Mitth. 1881, p. 531.

$\S$ Bull. Soc. Min. de France, 1883, p. 260.

Phil. Mag. S. 5. Vol. 18. No. 111. Aug. 1884. K 
of hemihedrism, if observed, would be accompanied by circular polarization *. The crystals of sal-ammoniac did not show it. In the case of cuprite, although many crystals transmit light in irregular patches between crossed Nicols, there is no evidence of circular polarization.

Note.-The cleavage of cuprite is stated in the text-books to be octahedral. The specimens examined on the present occasion show, in addition to the uneven and interrupted octahedral cleavage, a bright and perfect cleavage parallel to the faces of the cube.

XVI. On the Colour of Chemical Compounds, chiefly as a Function of the Atomic Weights of their Constitrent Elements. - Part I. Inorganic Compounds. By Thomas Carneluey, D.Se. (London), Professor of Chemistry in University College, Dundeet.

THERE are at least three circumstances which condition the colour of chemical compounds, viz.:-

1. Temperature.

2. The quantity of the electro-negative element present in a binary compound.

3. The atomic weights of the constituent elements of the compound.

Of these, the first two, together with a few other points in this connexion, have been studied in some detail by Delaval Talbot $\S$, Brewster\|, Schönbeinף, Gladstone**, Houston $\dagger \dagger$, Ackroyd $\ddagger$, Petrie§§, Ross\|\|, and Bayley $\|$ \%. Though it is to the third of these circumstances that I wish more particularly to direct attention in the present communication, yet it

* Groth, Physizalische Krystallographie, 1876, p. 223; Von Lang, Lehrbuch der Krystallographie, 1866, p. 114.

$\dagger$ Communicated by the Author.

I "An experimental Enquiry into the Cause of the Permanent Colours of Bodies," Manchester Phil. Soc. Mem. ii. pp. 147-272 (1789).

\$ "Chemical Changes in Colour," Phil. Mag. [3] ii. p. 359 (1833).

II "Colour of Natural Bodies," Phil. Mag. [3] viii. p. 468 (1886).

If "Canse of the Change in Colour which many Substances exhibit under the Action of Heat," Pogg. Ann. xlv. p. 263 (1838); "Colour Changes," Erdm. Prak. Chem. lxi. p. 193 (1854); "On the Influence of Temperature on the Colour of Substances," Basel Verhandl. i. p. 13 (1857).

** "Effect of Heat on the Colour of Salts in Solution," Phil. Mag. [4] xiv. p. 422 (1857); "Colour of Chloride of Copper in different States of Hydration," Chem. Soc. Journ, viii. p. 211 (1856).

$\dagger \dagger$ "Change of Colour produced in certain Chemical Compounds by Heat," Franklin Instit. Journ. 1xii. pp. 115-127 (1871).

扭 "Mletachromatism," Chem. News, xxxiv. p. 76(1876); Nature, xiii. pp. 298,385 (1876); "Selective Absorption," Phil. Mag. [5] ii.p.423 (1876).

\$ "Metachromatism," Nature, xiii. pp. 347, 426 (1876).

Chem. News, xxxiv. pp. 108, 132; also 'Pyrology', p. 114

919. "Colour Properties and Colour Relations of the Iron-Copper Group," Chem. Soc. Journ. xxxix. p. 362 (1881). 
Phil. Mags. S. 5.Vol .18. P1.VI.

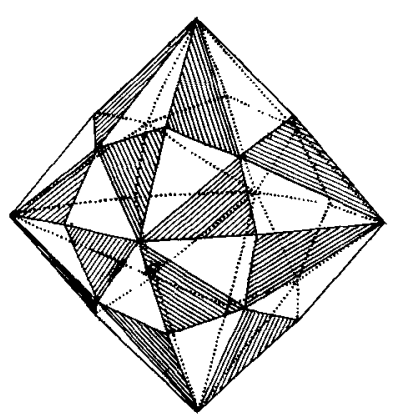

Fig. 1 .

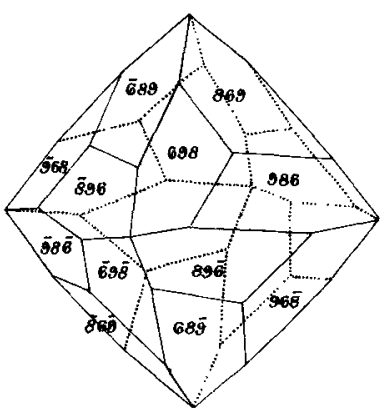

Fig. 2.

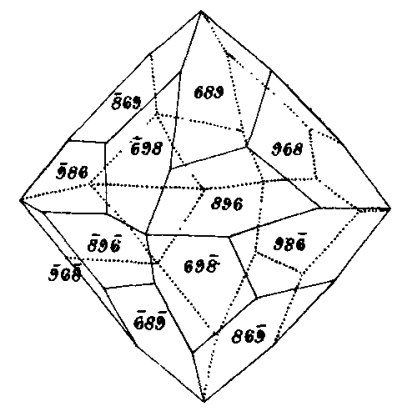

Fig. 3.

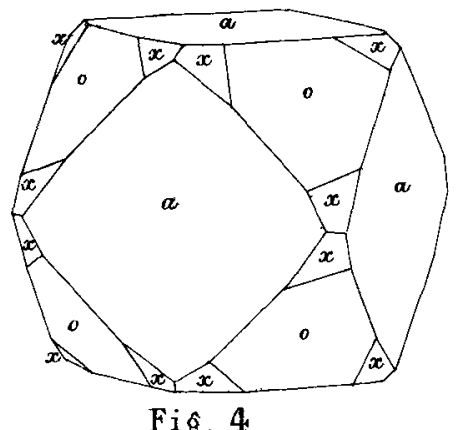

Fî̀. 4

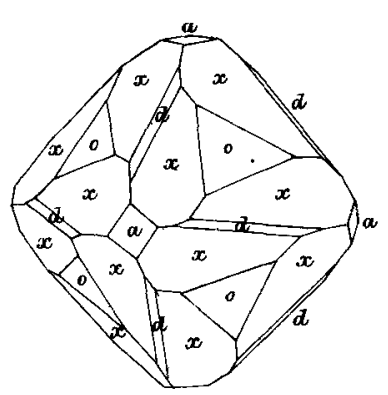

Fig. 5.

Guprite. 